Brit. J. industr. Med., 1965, 22, 210.

\title{
EXPERIMENTAL INVESTIGATION OF THE EFFECTS OF DIRECT CURRENT ELECTRIC SHOCK ON RESPIRATION
}

\author{
BY \\ A. L. ANGELIS*, W. R. LEE, and S. ZOLEDZIOWSKI \\ From the Nuffield Department of Occupational Health, University of Manchester, and the Department \\ of Electrical Engineering, Royal College of Advanced Technology, Salford
}

(RECEIVED FOR PUBLICATION FEBRUARY 12, 1965)

\begin{abstract}
Direct current electric shocks were applied along the forelimb to forelimb pathway in rabbits. The effects on respiration were found to depend on the current value, which from this point of view can be divided into four ranges.

Range I, in which there was no effect on respiration, included currents up to $50 \mathrm{~mA}$. In range II (currents from $50 \mathrm{~mA}$ to $180 \mathrm{~mA}$ ) there was arrest of respiration during the early part of the shock. In range III the current was from $180 \mathrm{~mA}$ to $350 \mathrm{~mA}$, and respiration was arrested throughout the shock with spontaneous resumption immediately afterwards. In range IV the current was from $350 \mathrm{~mA}$ upwards (the highest current in this series was $1.8 \mathrm{~A}$ ) and resulted in arrest of respiration throughout the shock followed by a delay before spontaneous resumption of respiration.

A number of animals in range IV died without breathing again after the end of the shock. In these cases death could be explained by ventricular fibrillation, by asphyxia resulting from the long duration of the shock, or by the fact that the shocks were the last of a series at high currents producing marked damage.
\end{abstract}

The description of closed-chest cardiac massage by Kouwenhoven, Jude, and Knickerbocker (1960) has renewed interest in the effects and treatment of electric shock.

Most recent experimental work on electric shock has been done using alternating current (A.C.) because this current is more commonly used than direct current (D.C.) (Kouwenhoven, Knickerbocker, Chesnut, Milnor, and Sass, 1959; Lee and Zoledziowski, 1964). No references have been traced to the experimental study of D.C. electric shock since the work carried out by Prevost and Batelli (1899) and by Cunningham (1899). Those experiments were not designed to investigate the effects of the shock on respiration but to study the mechanism of death, any observations on the effects on respiration being incidental.

The present investigation was planned to study the effects on respiration of direct current passed between the forelimbs.

\section{Experimental Technique}

Rabbits were used in these experiments because they frequently defibrillate spontaneously. This allowed the effects of electric shock on respiration to be separated from the consequences of ventricular fibrillation, sometimes induced by the shock.

The animals were anaesthetized with intravenous sodium pentobarbital (Nembutal, Abbott) dissolved in water to $20 \mathrm{mg}$. $/ \mathrm{ml}$. A tracheal cannula was tied in place and connected with the pneumotachograph to a multichannel ultraviolet recorder. $\dagger$

To record the blood pressure, a $1 \mathrm{~mm}$. internal diameter polythene cannula was inserted into a common carotid artery. The cannula was connected through a saline-filled system to an inductance manometer (type 1025) which was connected to the recorder through an A.C. amplifier. After the cannula had been inserted, the animal was given $0.3 \mathrm{ml}$. of heparin intravenously.

The electrocardiogram (E.C.G.), shock duration, and, in some experiments, the current magnitude were simultaneously recorded on other channels. In the remaining

"Present address: 75 Hippocratus St., Athens 144, Greece.

†New Electronic Products Ltd. 1050. 


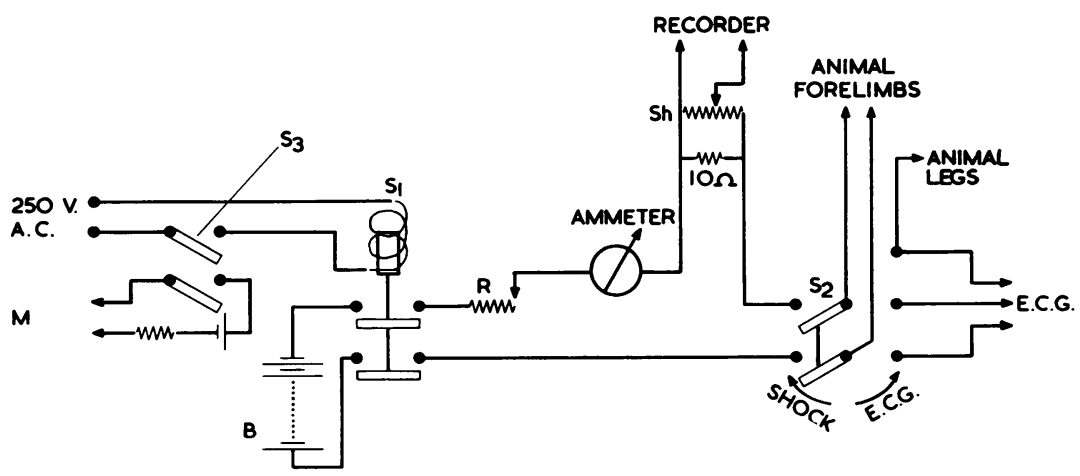

Fig. 1.-Circuit diagram

$S_{1}$ Mains operated switch constructed to break 2A D.C. at $1500 \mathrm{~V}$

$S_{2}$ Change-over switch

$S_{2}$ Shock actuator

$\mathrm{S}_{3}$ Twock actuator $120 \mathrm{~V}$ each

B Twelve batteries $120 \mathrm{~V}$ each $400 \mathrm{~V}$

M Shock marker

Sh Current shunt

experiments only the start and finish of the shock were recorded. Respiration, blood pressure, and E.C.G. were continuously monitored on oscilloscopes during the experiment, except that the E.C.G. was disconnected during the shock. At each experimental run blood pressure calibration records at 0,100 , and $200 \mathrm{~mm}$. $\mathrm{Hg}$ were made. Within these limits the recording system had an approximately linear response. This was satisfactory since an absolute measure of the blood pressure was not required. Similarly, in those experiments in which the current value was continuously recorded, calibration measurements of the current were made. The duration of the shock was determined from the one-second signals of the timer incorporated in the recorder. Current strength and duration formed the two variables of the applied stimulus and were changed independently of one another.

The source of the current was dry batteries which were connected in the circuit shown in Figure 1. Electrodes were fixed to the animal by the method used by Lee and Zoledziowski (1964).

Several shocks were sometimes given to the same animal. In order to provide an estimate of the pre-shock condition the blood pressure was noted before the first shock and immediately before each subsequent shock.

\section{RESULTS}

\section{Respiration}

Effects of Making and Breaking the Circuit.Making or breaking the circuit caused a sudden respiratory movement in 69 of the 71 experiments. This occurred on making the circuit at $12.5 \mathrm{~mA}$, the lowest current used, whereas $68 \mathrm{~mA}$ was the lowest current with which it occurred on breaking the circuit. In one animal the respiratory movement was observed only on breaking the circuit, although the currents used were high $(600 \mathrm{~mA}, 850 \mathrm{~mA}, 1 \mathrm{~A})$.

Effects of Sustained Current.-The phenomena which a sustained D.C. electric shock produced on respiration may be grouped as follows:

(a) No Arrest of Respiration.-An example is shown in Figure 2. This effect was observed with currents ranging from 0 to $50 \mathrm{~mA}$.

(b) Arrest of Respiration during the Early Part of the Shock.-This phenomenon is illustrated in Fig. 3 and was observed with currents from 50 to $180 \mathrm{~mA}$. It occurred on 18 occasions, on 16 of which respiration was resumed within 20 seconds.

(c) Arrest of Respiration throughout the Shock, with Spontaneous Resumption immediately afterwards.-Figure 4 illustrates this phenomenon which was observed with currents ranging from $180 \mathrm{~mA}$ to $350 \mathrm{~mA}$.

(d) Arrest of Respiration throughout the Shock and Delay before Spontaneous Resumption of Respiration.-This was observed without circulatory arrest (Fig. 5) and with circulatory arrest (Fig. 6). In the experiment illustrated, respiration was arrested for the duration of the shock; $5.5 \mathrm{sec}$. after the end of the shock there was one respiration. The blood pressure began to fall immediately the shock started; after the shock it was $12 \mathrm{~mm}$. Hg. The E.C.G. tracing, which appeared $8 \mathrm{sec}$. after the shock, showed ventricular fibrillation.

(e) Permanent Arrest of Respiration (death).-The mechanism of death is discussed separately.

These effects are summarized in Table 1. It should be noted that there was some overlap of current between the different groups. 


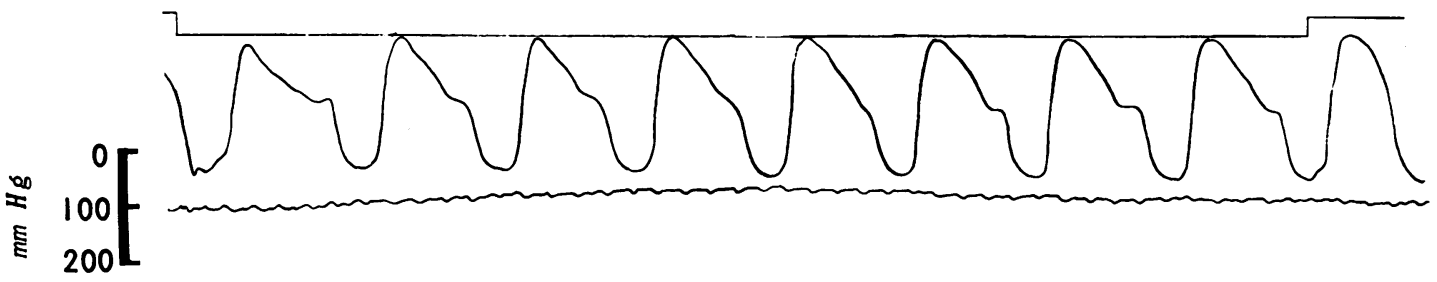

FIG. 2.-2.77 kg. animal, $25 \mathrm{~mA}$ for $10.5 \mathrm{sec}$.; fourth shock. Recording speed $1 \mathrm{in} . / 1 \mathrm{sec}$. From above down: stimulus, respiration, blood pressure. Blood pressure before first shock $100 \mathrm{~mm}$. $\mathrm{Hg}$; before this shock $100 \mathrm{~mm}$. Hg.

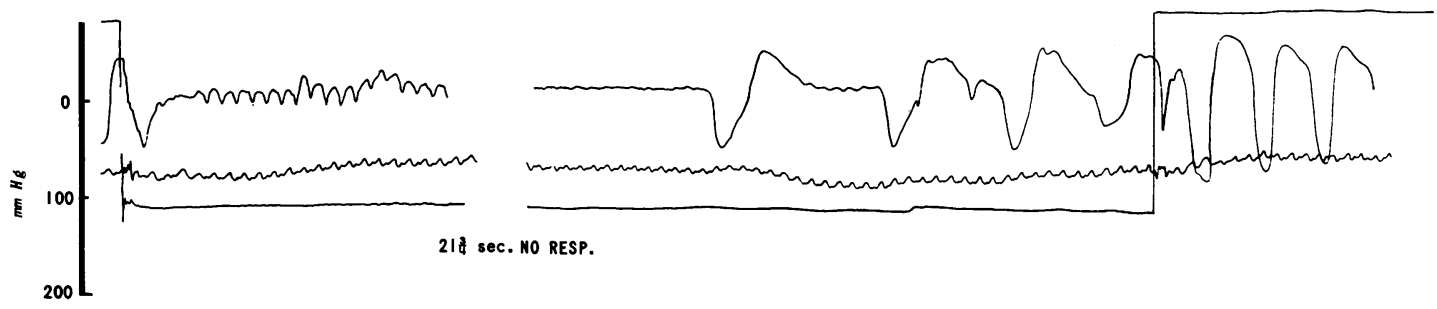

FIG. 3. $-3.40 \mathrm{~kg}$. animal, 160-173 $\mathrm{mA}$ for $29 \mathrm{sec}$; eighth shock. Recording speed 1 in./1 sec. From above down: stimulus, respiration, blood pressure. Blood pressure before first shock $86 \mathrm{~mm}$. $\mathrm{Hg}$; before this shock $84 \mathrm{~mm}$. $\mathrm{Hg}$.
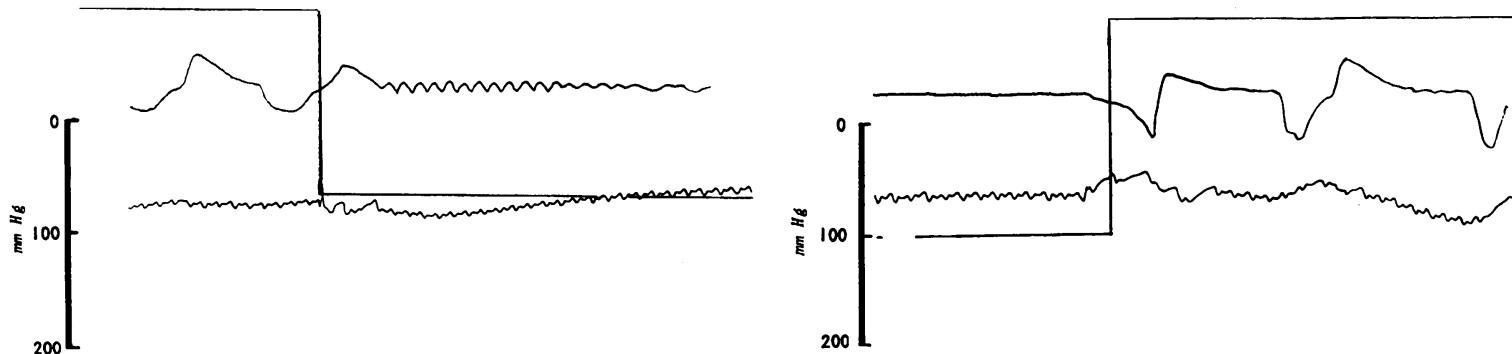

FIG. 4.-3.20 kg. animal, 291-315 $\mathrm{mA}$ for $30.5 \mathrm{sec}$; first shock.

Recording speed 1 in./1 sec. From above down: stimulus, respiration, blood pressure. Blood pressure before the shock $78 \mathrm{~mm}$. $\mathbf{H g}$.

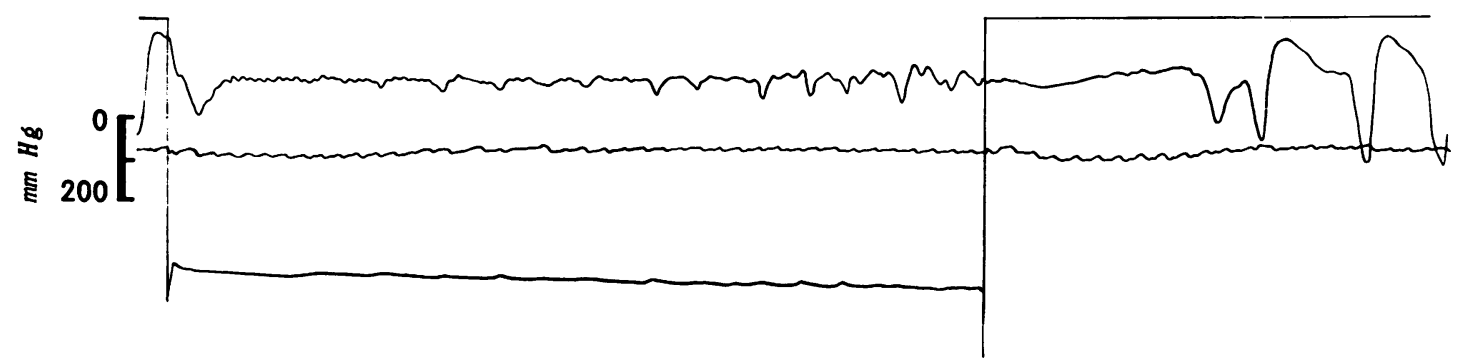

FIG. 5.-2.77 kg. animal, 400-423 $\mathrm{mA}$ for $10 \mathrm{sec}$; eighth shock. Recording speed 1 in./1 sec. From above down: stimulus, respiration, blood pressure. Blood pressure before first shock $100 \mathrm{~mm}$. $\mathrm{Hg}$; before this shock $93 \mathrm{~mm}$. Hg. 


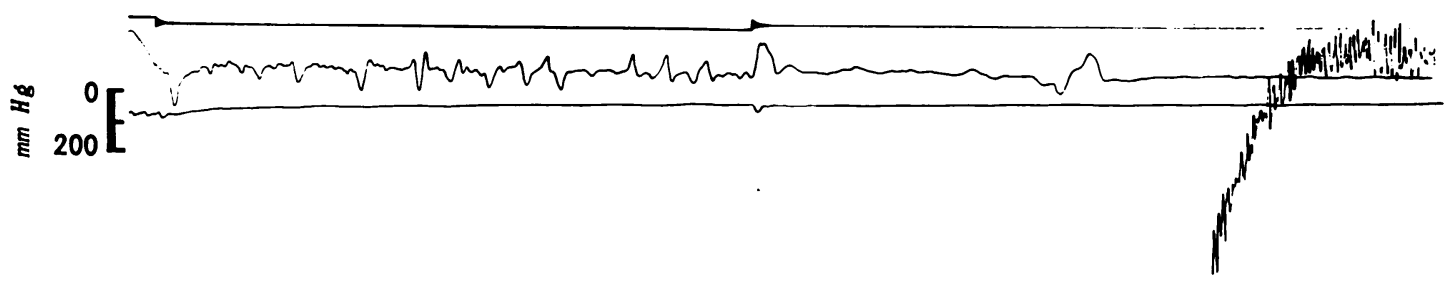

FIG. 6.-2.77 kg. animal, $880-890 \mathrm{~mA}$ for $10 \mathrm{sec}$; tenth shock. Recording speed 1 in./1 sec. From above down: stimulus, respiration, blood pressure, E.C.G. Blood pressure before first shock $100 \mathrm{~mm}$. $\mathbf{H g}$; before this shock $75 \mathrm{~mm}$. Hg.

TABLE 1

SUMMARY OF CURRENT RANGES ASSOCIATED WITH RESPIRATORY EFFECTS

\begin{tabular}{l|l}
\hline Current (mA) & \multicolumn{1}{c}{ Respiratory Effects } \\
\hline 0 to 50 & $\begin{array}{l}\text { No arrest of respiration } \\
50 \text { to } 180\end{array}$ \\
180 to 350 & $\begin{array}{l}\text { Arrest of respiration at the start of the shock } \\
\text { and resumption during the shock } \\
\text { Respiration arrested during the shock and } \\
\text { started again immediately afterwards } \\
\text { Arrest of respiration during the shock and delay } \\
\text { before restoration of the respiratory function }\end{array}$ \\
\hline
\end{tabular}

All but one of the deaths occurred with currents in the last range.

\section{Heart}

Although this study is concerned with the effects of direct current on respiration, ventricular fibrillation produced by the current will be briefly considered. Ventricular fibrillation appeared in range IV; the lowest current at which it was observed was 425-455 mA.

The E.C.G. could not be recorded until several seconds after the end of the shock; therefore if fibrillation occurred before the reappearance of the E.C.G., its presence had to be estimated by other signs. It was presumed that fibrillation started at the moment when a rapid fall in blood pressure occurred and when the pulse wave disappeared.
Fibrillation produced by the direct effect of the current on the heart was observed in nine cases (Table 2). Fibrillation occurred six times with currents between $425 \mathrm{~mA}$ and $1 \mathrm{~A}$. On five of these occasions it appeared some time after the start of the shock and only once on making the circuit. With higher currents, between 1.35 A and 1.7 A, fibrillation appeared at the making of the circuit. (With an even greater current of $1.8 \mathrm{~A}$, fibrillation appeared on breaking the circuit. This was the only occasion when a current of this magnitude was used. This experiment has otherwise been excluded, because a satisfactory record of respiration was not obtained.)

It is known that to produce ventricular fibrillation the current must pass during the relative refractory period of the ventricular muscle, corresponding to the T wave of the E.C.G. (Ferris, King, Spence, and Williams, 1936; Kouwenhoven et al., 1959). In this series of experiments no attempt has been made to relate the making or the breaking of the circuit with the cardiac cycle.

Figure 7 is an example of circulatory arrest. The respiration was arrested for the duration of the shock and did not start again. Seven seconds after the start of the shock the blood pressure began to fall. At the end of the shock it was $25 \mathrm{~mm}$. $\mathrm{Hg}$. The E.C.G., which reappeared $20 \mathrm{sec}$. after the end of the shock, showed ventricular fibrillation; $40 \mathrm{sec}$. after the end of the shock defibrillation was carried out by

TABLE 2

VENTRICULAR FIBRILLATION WITH DIRECT CURRENT SHOCKS

\begin{tabular}{|c|c|c|c|c|c|c|c|c|c|}
\hline \multirow[b]{2}{*}{$\underset{(m A)}{\text { Current }}$} & \multirow[b]{2}{*}{$\begin{array}{c}\text { Shock } \\
\text { Duration } \\
\text { (sec.) }\end{array}$} & \multirow[b]{2}{*}{$\begin{array}{c}\text { Weight } \\
\text { (kg.) }\end{array}$} & \multirow[b]{2}{*}{$\begin{array}{c}\text { Shock } \\
\text { No. }\end{array}$} & \multicolumn{4}{|c|}{ Fibrillation } & \multirow[b]{2}{*}{$\begin{array}{l}\text { Spontaneous } \\
\text { Defibrillation } \\
\text { (sec. after } \\
\text { end of shock) }\end{array}$} & \multirow[b]{2}{*}{ Death } \\
\hline & & & & $\begin{array}{c}\text { During } \\
\text { the } \\
\text { Shock }\end{array}$ & $\begin{array}{l}\text { Time } \\
\text { from } \\
\text { Start } \\
\text { (sec.) }\end{array}$ & $\begin{array}{c}\text { On } \\
\text { Making } \\
\text { the } \\
\text { Circuit }\end{array}$ & $\begin{array}{c}\text { On } \\
\text { Breaking } \\
\text { the } \\
\text { Circuit }\end{array}$ & & \\
\hline $\begin{array}{l}425-455 \\
320-460 \\
500-480 \\
880-890 \\
930 \\
900-1000\end{array}$ & $\begin{array}{l}25 \\
20 \cdot 5 \\
27 \\
10 \\
15 \cdot 5 \\
11\end{array}$ & $\begin{array}{l}2 \cdot 62 \\
2 \cdot 90 \\
4 \cdot 00 \\
2 \cdot 77 \\
3 \cdot 20 \\
3 \cdot 30\end{array}$ & $\begin{array}{r}8 \\
2 \\
9 \\
10 \\
5 \\
3\end{array}$ & $\begin{array}{l}+ \\
+ \\
+ \\
+ \\
+\end{array}$ & $\begin{array}{c}14 \cdot 25 \\
5 \cdot 75 \\
7 \\
3 \cdot 25 \\
7\end{array}$ & + & & & $\begin{array}{l}+ \\
+ \\
+ \\
+ \\
+ \\
+\end{array}$ \\
\hline $\begin{array}{l}1350 \\
1620 \\
1700\end{array}$ & $\begin{array}{l}2 \\
2 \cdot 5 \\
6 \cdot 25\end{array}$ & $\begin{array}{l}3 \cdot 60 \\
3 \cdot 60 \\
3 \cdot 60\end{array}$ & $\begin{array}{l}1 \\
3 \\
4\end{array}$ & & & $\begin{array}{l}+ \\
+ \\
+\end{array}$ & & $\begin{array}{l}15 \\
3.5 \\
11\end{array}$ & + \\
\hline
\end{tabular}




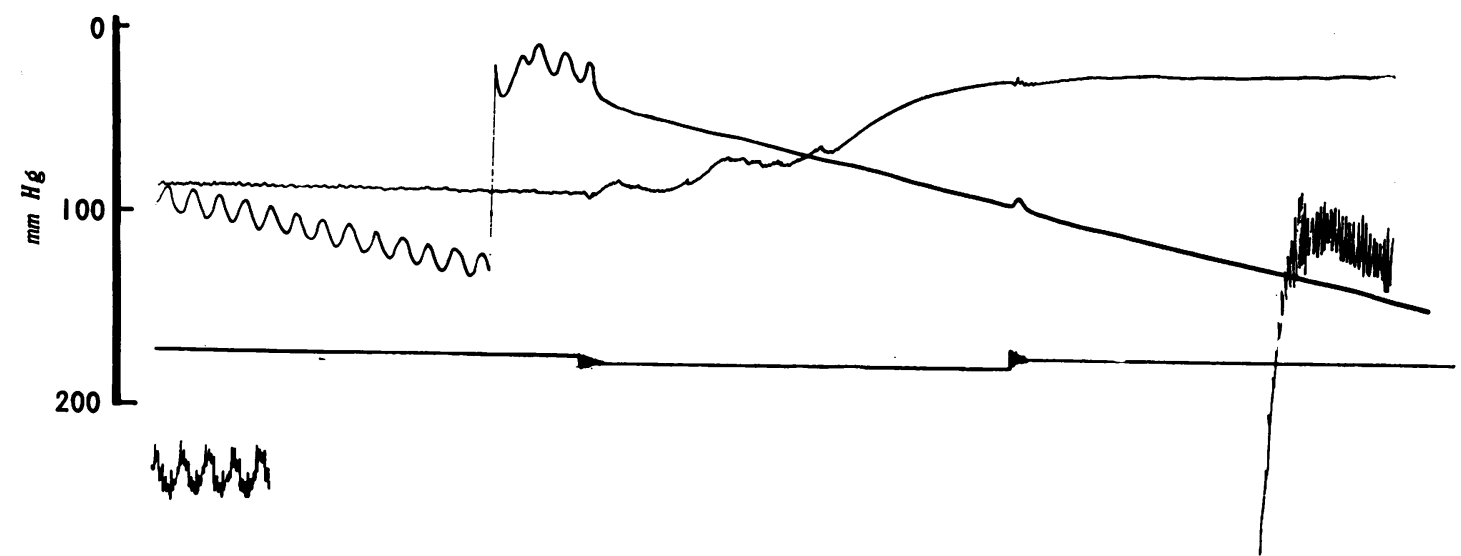

Fig. 7.-3.30 kg. animal, $900 \mathrm{mA-1}$ A for $11 \mathrm{sec}$; third shock. Recording speed 0.3 in./1 sec. From above down: blood pressure, respiration, stimulus, E.C.G. (the slope on the respiration trace is due to electronic 'drift' and has no physiological significance). Blood pressure before first shock $92 \mathrm{~mm}$. $\mathrm{Hg}$; before this shock $91 \mathrm{~mm}$. $\mathbf{H g}$.

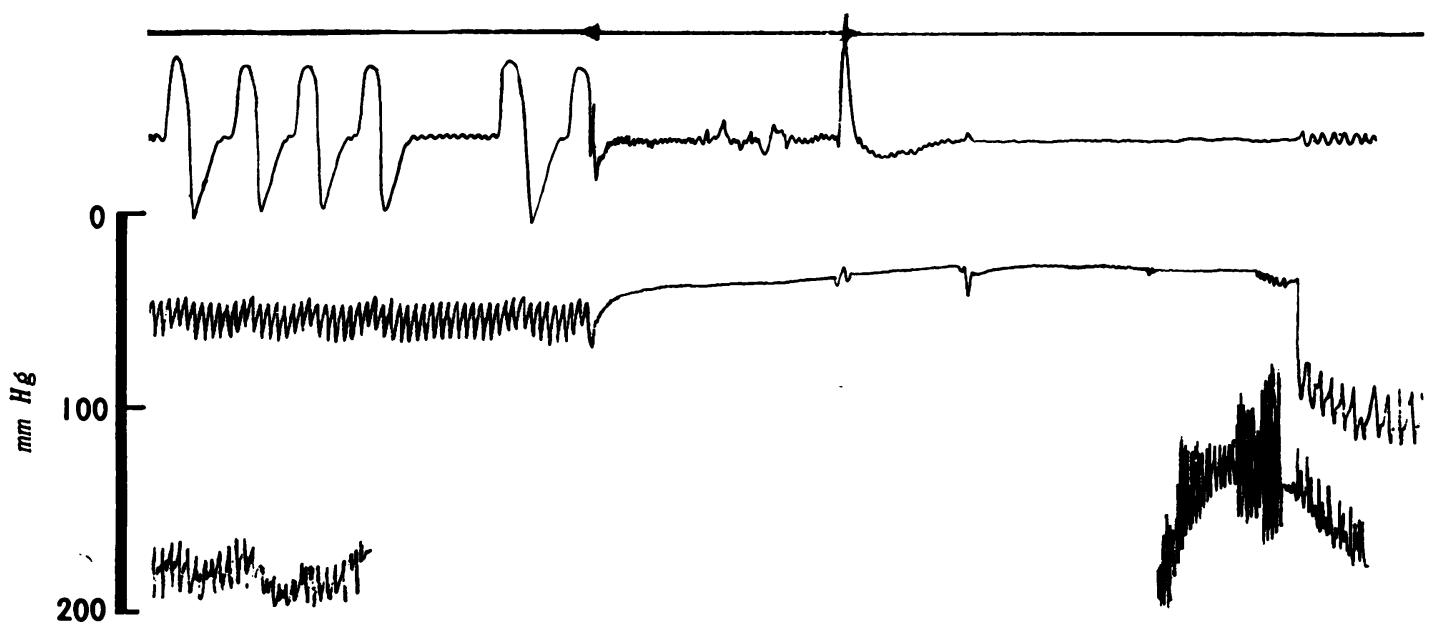

Fig. 8.-3.60 kg. animal, 1.7 A for 6.25 sec.; fourth shock. Recording speed 0.3 in./1 sec. From above down: stimulus, respiration, blood pressure, E.C.G. Blood pressure before first shock $91 / 72 \mathrm{~mm}$. Hg; before this shock $57 / 40 \mathrm{~mm}$. $\mathrm{Hg}$.

injection of procainamide through the carotid cannula but the blood pressure did not rise again.

\section{Mechanism of Death}

The deaths from electric shock in this series will be considered from the point of view of the effects of direct current on respiration. Those cases in which the mechanism of death is not clear will be discussed further.

There were 13 deaths, of which six were due to ventricular fibrillation resulting directly from the current. The other seven deaths were the following:

(1) A shock of $1.7 \mathrm{~A}$ for $6.25 \mathrm{sec}$., the fourth shock (Fig. 8). There was permanent arrest of respiration. At the start of the shock the blood pressure fell quickly and the pulse wave disappeared. At the end the blood pressure was $23 \mathrm{~mm}$. $\mathrm{Hg}$. The E.C.G., which reappeared $8 \mathrm{sec}$. after the end of the shock, showed ventricular fibrillation. Three seconds later the E.C.G. showed spontaneous defibrillation and the blood pressure rose to $71 \mathrm{~mm}$. $\mathrm{Hg}$. Some $57 \mathrm{sec}$. after the end of the shock the blood pressure fell again and within 21 seconds it was $15 \mathrm{~mm}$. $\mathrm{Hg}$.

This animal had reacted in an unusual manner to the anaesthetic. After being anaesthetized and before the first shock respiration had stopped and artificial respiration was applied for $30 \mathrm{~min}$. before breathing restarted. It may be that death was hastened by the effects, on the already affected respiratory centre, of anoxia resulting from ventricular fibrillation. Also this was the fourth shock on 
the same animal; three were with very large currents of $1.35 \mathrm{~A}, 1.62 \mathrm{~A}$, and $1.7 \mathrm{~A}$, and it is probable that damage had already occurred and contributed to the death. The blood pressure, which before the shock was $91 / 72 \mathrm{~mm}$. $\mathrm{Hg}$, had fallen to $57 / 40 \mathrm{~mm}$. $\mathrm{Hg}$ at the beginning of this shock.

(2) Ventricular fibrillation occurred $10 \mathrm{sec}$. after a shock of $1.45 \mathrm{~A}$ for 2.5 seconds. This was the second shock to this animal. Respiration started again $14 \mathrm{sec}$. after the end of the shock and continued for $111 \mathrm{sec}$. while the animal was fibrillating. Death was certainly not due to primary arrest of respiration.

$(3,4)$ There were two cases in which death was probably caused by anoxia resulting from arrest of respiration produced by prolonged tetanic contraction of the respiratory muscles. The duration of the shocks was long and the current magnitude was large (507 mA for $62 \mathrm{sec}$.; $420 \mathrm{~mA}$ for $90 \mathrm{sec}$.). A contributory factor in the first case could have been damage caused by repeated shocks. It was the fifteenth shock; the blood pressure before the first shock was $86 \mathrm{~mm}$. $\mathrm{Hg}$, and before this shock $77 \mathrm{~mm}$. $\mathrm{Hg}$. The second case was a first shock.

(5) This animal had been subjected to three previous shocks of $100 \mathrm{~mA}$ without any effect on respiration, the last of these being for 130 seconds. During the fourth shock (100 mA for $294 \mathrm{sec}$.) respiration was arrested for the first $11 \mathrm{sec}$. of the shock, after which it started again but was irregular. Respiration became weaker, and $13 \mathrm{sec}$. before the end of the shock there was a complete respiratory arrest. This pattern of weak respirations after the breakthrough was not observed on any other occasion. In this experiment the carotid cannula was blocked and it is not known what happened to the blood pressure. The E.C.G. was normal.

It is probable that death was primarily due to anoxia caused by decreased respiratory movements resulting from partial tetanic contraction of the respiratory muscles. This effect of some of the respiratory muscles being in tetanic contraction has been observed with alternating currents (Lee and Zoledziowski, 1964).

(6) The shock was of $430 \mathrm{~mA}$ for $15 \mathrm{sec}$.; it was a second shock. Respiration started again spontaneously $2.5 \mathrm{sec}$. after the end of the shock and continued for several minutes. Death was therefore not due to direct inhibition of the respiratory centre by the shock current.

(7) Here (480-550 mA for $30.5 \mathrm{sec}$., seventh shock) it is also very difficult to explain the mechanism of death. There was respiratory arrest during the shock; $3.5 \mathrm{sec}$. after the end of the shock there was one respiration. The blood pressure immediately after the shock was $97 / 62 \mathrm{~mm}$. Hg. Several seconds later fibrillation occurred. Defibrillation occurred during closed-chest cardiac massage, and the animal restarted breathing and died a short time later. Because of the one respiration after the end of the shock, and because respiration was spontaneously restored during the closed-chest cardiac massage, it appears improbable that death was due to a direct action of the current on the respiratory centre. In this shock the current was large and the time relatively long, and it was the seventh shock so the animal may well have suffered previous damage. The blood pressure before the first shock was $118 / 100$ and before this shock $91 / 73 \mathrm{~mm}$. $\mathrm{Hg}$.

Thus in none of these 13 deaths could the effect of the current on the respiratory centre be clearly incriminated as a cause of death.

\section{Discussion}

Arrest of Respiration during the Shock.-Arrest of respiration occurred both with and without breakthrough.

There are two possible explanations of arrest of respiration with breakthrough. First, stimulation of the cutaneous skin receptors in the current pathway might cause the respiratory arrest. François (1955) compared this effect with respiratory arrest on sudden immersion in cold water. Secondly, Lee and Zoledziowski (1964) suggested tetanic contraction of some but not all the respiratory muscles. Those muscles unaffected come into action when stimulation from the accumulated $\mathrm{CO}_{2}$ and other metabolites is sufficiently strong.

The arrest of respiration throughout the whole duration of A.C. shock is clearly due to tetanic contraction of the muscles. In the present series of experiments with D.C. it was noticed that above $180 \mathrm{~mA}$ all the muscles of the body, including the respiratory muscles, were held in tetanic contraction. Consequently the arrest of respiration throughout the shock was due to tetanic contraction of the respiratory muscles. Other workers have also made this observation with direct current. Cunningham (1899) observed tetanic contractions and the breakthrough phenomenon even when a current of $1.6 \mathrm{~A}$ was passed directly through the cerebrum, medulla, and upper cord. Prevost and Battelli (1899) also noticed sustained contraction of the muscles and the arrest of respiration with breakthrough during direct current shock with the electrodes on the mouth and rectum. Why tetanic contraction should occur with direct current is not easily explained. The problem is now being investigated.

Delay of Respiration after the End of the Shock.The delay before spontaneous resumption of 
respiration after the end of the shock has been noticed previously with direct current by Cunningham (1899) and by Prevost and Battelli (1899), and with alternating current by Urquhart (1927), Urquhart and Noble (1929), and Lee and Zoledziowski (1964), and it has recently been studied by Lee, Zoledziowski, and Dingwall-Fordyce (1965).

In the present series of experiments this phenomenon appeared with or without ventricular fibrillation. Delay was observed in current ranges III and IV; the smallest current was $244 \mathrm{~mA}$. Urquhart (1927), using alternating current, noticed a temporary block of the respiratory centre when it was included in the pathway of the current. Lee and Zoledziowski (1964) observed this effect above $200 \mathrm{~mA}$ when using alternating current along the same pathway as that employed in the present study. Possible mechanisms were discussed by Lee et al. (1965), and the present study adds nothing to confirm or disprove the suggestions put forward.

Comparison with Alternating Current.-The major effects on respiration of direct current electric shock (arrest of respiration with breakthrough during the shock; complete respiratory arrest; delay in spontaneous resumption of respiration after the shock) have also been observed with alternating current (Lee and Zoledziowski, 1964; Lee et al., 1965). Comparing the results, it is found that some effects were produced by smaller alternating than direct currents. This is in keeping with the finding of Dalziel, Ogden, and Abbott (1943) that persons were held on to a current-carrying conductor by smaller alternating than direct currents. Likewise Ferris and his colleagues (1936) showed that ventricular fibrillation had a lower threshold to alternating than to direct current.

\section{Conclusions}

The effects of forelimb to forelimb direct current shocks on respiration bear a strong relation to the current magnitude and could be best correlated with four ranges of currents.

Above certain currents, ventricular fibrillation may appear as a direct effect of the current on the heart.

None of the 13 deaths appeared to be due to a direct action of the current on the respiratory centre leading to immediate and permanent arrest of respiration.

The effects observed were the same as with alternating currents, but somewhat greater direct currents were required to produce them.

We are grateful to Dr. J. B. L. Howell of the Department of Medicine, University of Manchester, for the use of the apparatus with which these experiments were made. The Department of Medical Illustration of Manchester Royal Infirmary prepared the illustrations from our recordings.

\section{REFERENCES}

Cunningham, R. H. (1899). N.Y. med. J., 70, 581, 615.

Dalziel, C. F., Ogden, E., and Abbott, C. E. (1943). Elect. Engineering $(N . Y),$.62 , Trans. p. 745.

Ferris, L. P., King, B. G., Spence, P. W., and Williams, H. B. (1936). Ibid., 55, 498.

François, R. C. (1955). Occup. Safety Hlth, 5, 5.

Kouwenhoven, W. B., Jude, J. R., and Knickerbocker, G. G. (1960). J. Amer. med. Ass., 173, 1064.

—, Knickerbocker, G. G., Chesnut, R. W., Milnor, W. R., and Sass, D. J. (1959). Trans. Amer. Inst. Electr. Engrs.: Part 1. Communication and Electronics (1959-60), p. 163.

Lee, W. R., and Z.oledziowski, S. (1964). Brit. J. industr. Med., 21, 135 .

,$--\frac{13}{2}$ and Dingwall-Fordyce, I. (1965). Ibid., 22, 43.

Prevost, J. L., and Battelli, F. (1899). J. Physiol. Path. gén., 1, 689.

Urquhart, R. W. I. (1927). J. industr. Hyg., 9, 140.

- and Noble, E. C. (1929). Ibid., 11, 154. 